\title{
Prevalence and Clinical Profile of Chiari network in Bangladeshi subjects: Analysis of 1832 subjects by Echocardiography
}

AKM Monwarul Islam ${ }^{1}$, Rakesh Gupta ${ }^{2}$, Abdullah AS Majumder ${ }^{3}$, Mohammad Arifur Rahman ${ }^{1}$, Md. Toufiqur Rahman ${ }^{4}$, Mohammad Ullah ${ }^{4}$, Mohsin Ahmed ${ }^{1}$

${ }^{1}$ Department of Cardiology, National Institute of Cardiovascular Diseases, Dhaka, ${ }^{2}$ JROP Healthcare, Delhi \& Cardiologist, MAX Superspeciality Hospital, Delhi, ${ }^{3}$ Popular Diagnostic Centre Ltd., Dhaka, ${ }^{4}$ Col. Malek Medical College, Manikganj

Keywords: Chiari network, Embryonic Structures, Right Atrium, Bangladesh.

\begin{abstract}
:
Background: The Chiari network is mobile, serpentine, filament-like structures occasionally seen in right atrium near the opening of inferior vena cava and coronary sinus. Sometimes it may cause diagnostic confusion with right atrial pathologies.

Methods: This was a cross sectional study conducted from September 2017 to August 2018 in a private consultation center in Dhaka. All patients who underwent transthoracic echocardiography were included. Chiari network was diagnosed and any relevant clinical condition was recorded.

Results: Out of 1832 echo studies, Chiari network was found in 90 subjects giving a prevalence of $4.91 \%$. More than half (55.6\%) had otherwise normal heart, 20\% had ischaemic heart disease, $7.8 \%$ had cardiomyopathy, $6.7 \%$ congenital heart disease, while $3.3 \%$ had valvular heart disease.

Conclusion: The Chiari network is often an incidental diagnosis, though it may not be so rare. Clinicians should be aware of it to avoid diagnostic dilemma and to overcome difficulties while performing cardiovascular interventions.
\end{abstract}

(Cardiovasc. j. 2019; 11(2): 93-97)

\section{Introduction:}

The Chiari network is a mobile structure occasionally seen in the right atrium, most commonly encountered during echocardiography. It may be characterized as reticular network of fine strands attached to right atrium ${ }^{1}$ or, as membranous fenestration involving valve of inferior vena cava or coronary sinus, extending to crista terminalis and interatrial septum. ${ }^{2}$ Embryologically, it results from incomplete resorption of right valve of sinus venosus. Its prevalence has variably been reported to be $2-$ $13.6 \% .^{3-5}$

Traditionally, Chiari network has been considered as a benign anatomical entity having no clinical significance. Subsequently, the outlook has been challenged, and it has been reported to cause diagnostic confusion, ${ }^{6}$ be associated with diverse clinical conditions, ${ }^{7-9}$ or act as a physical barrier to invasive procedures. ${ }^{10}$ The prevalence of Chiari network in Bangladeshi subjects is not known. Also, data regarding its association with other conditions are scanty. Here, a study was carried out to find out the prevalence of Chiari network by trans-thoracic echocardiography in an outpatient population, and associated conditions have also been studied.

\section{Methods:}

The study was carried out in private consultation centres of Dhaka City during September 2017 to August 2018. All patients sent for

Address of Correspondence : Dr. AKM Monwarul Islam, Department of Cardiology, National Institute of Cardiovascular Diseases, Dhaka. E-mail: drmonwarbd@yahoo.com

(C) 2018 authors; licensed and published by International Society of Cardiovascular Ultrasound, Bangladesh Chapter and Bangladesh Society of Geriatric Cardiology. This is an Open Access article distributed under the terms of the CC BY NC 4.0 (https:// creativecommons.org/licenses/by-nc/4.0). 
transthoracic echocardiography were included. Echocardiographic examination was carried out by Vivid E95 (GE Healthcare, 9900 Innovation Drive, Wauwatosa, WI 53226, USA). The examination was carried out as per the recommendation of American Society of Echocardiography. Chiari network was sought for in all the standard views and also the modified views as needed. The network structures were arbitrarily classified into well-, moderately- and poorly-visualized on the basis of how organized they appear in $2 \mathrm{D}$ echocardiography.

\section{Results:}

In this study, 1832 subjects were examined. Majority of the patients with Chiari network belonged to middle-age group; $38.9 \%$ were $<40$ years of age while $34.4 \%$ were of $41-60$ years. Almost 2/3rds of the study subjects (63.3\%) were male. Out of 1832 echo studies, Chiari network was found in 90 subjects giving a prevalence of $4.91 \%$. Out of 90 , well-, moderately- and poorlyvisualized Chiari networks were 41 (45.6\%), 28 (31.1\%) and 21 (23.3\%), respectively. More than half $(55.6 \%)$ had otherwise normal heart, $20 \%$ had ischaemic heart disease, $7.8 \%$ had cardiomyopathy, $6.7 \%$ congenital heart disease, while $3.3 \%$ had valvular heart disease (Table I). In either sex, majority had otherwise normal heart. In male patients with Chiari network, IHD was the commonest diagnosis, whereas in female patients with Chiari network, cardiomyopathy was found most commonly, among those who have some sort of echo diagnosis. In younger age groups, Chiari network was more commonly associated with otherwise normal heart in echocardiography. As the age increases, probability of associated diseases increased, and beyond 80 years, all were associated with cardiac disease (Table II).
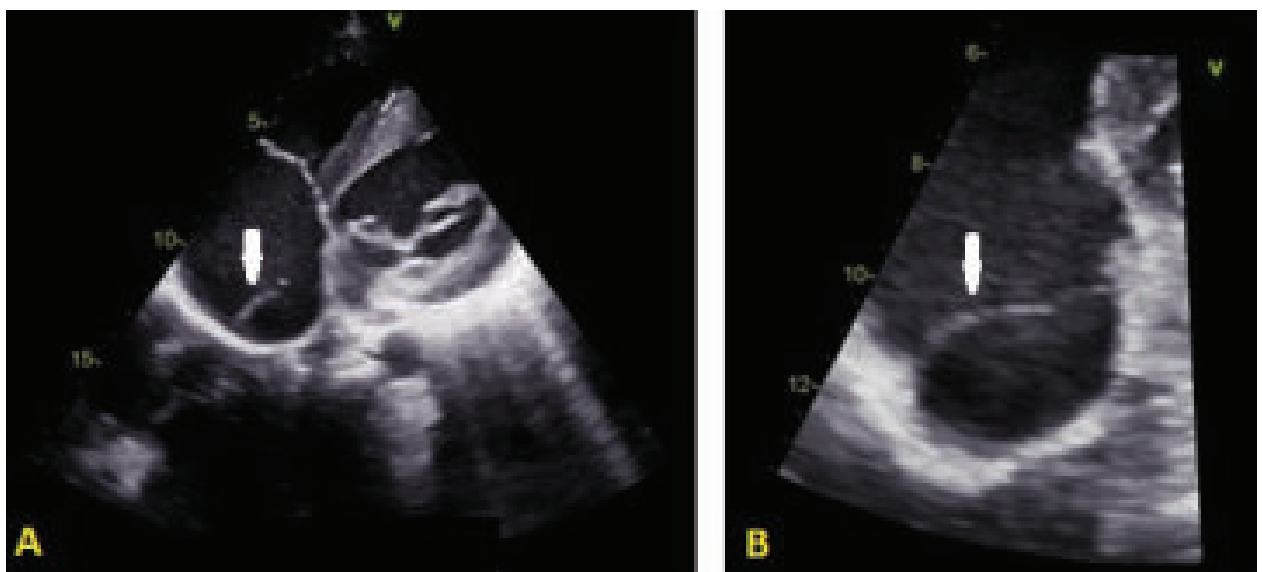

Fig 1: $2 D$ echocardiography showing Chiari network in right atrium in off-axis view (Panel A), and zoomed up view (Panel B), marked by white arrows.
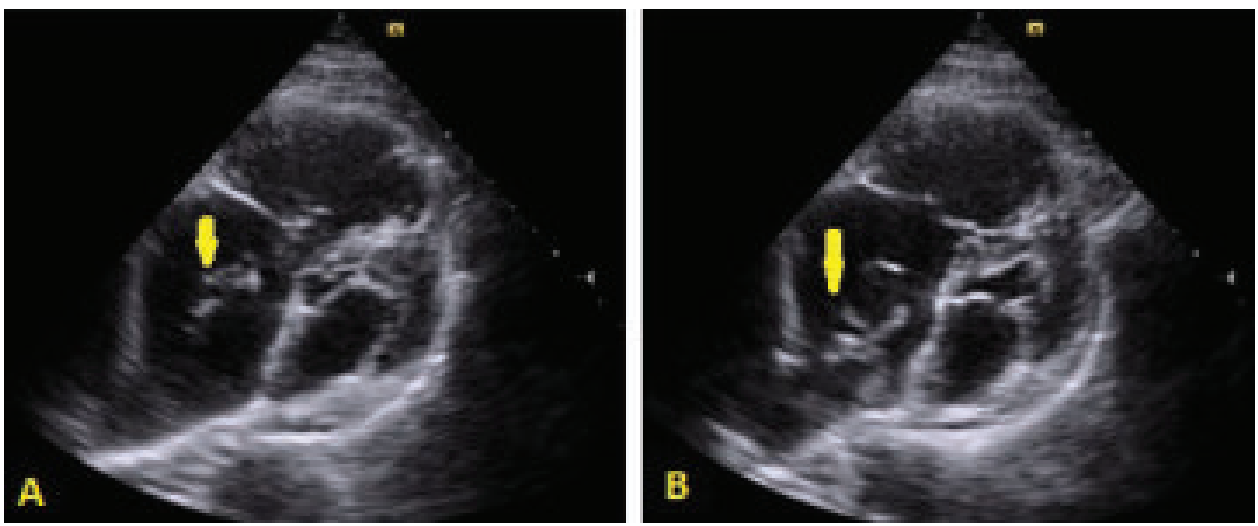

Fig 2: Panel A \& B: 2D echocardiography of a case of pulmonary thromboembolism showing Chiari network in dilated right atrium in different phases of off-axis views marked by yellow arrows. 

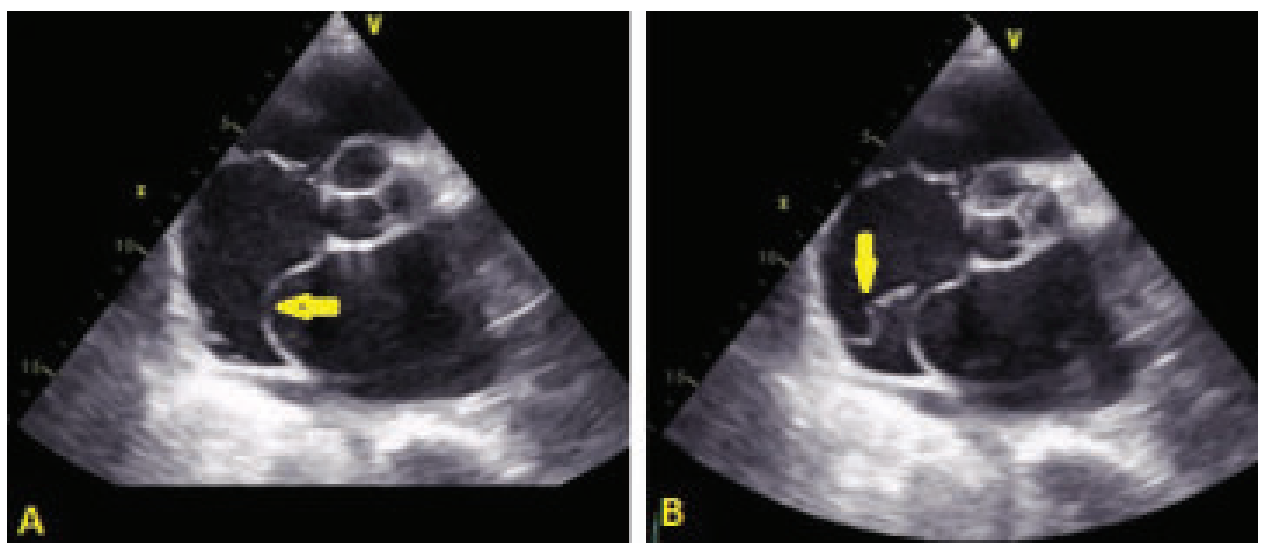

Fig.-3: $2 D$ echocardiography, parasternal short axis view. Panel A showing atrial septal aneurysm marked by arrow; Panel B showing Chiari network in right atrium marked by yellow arrow.

Table-I

Distribution of the study subjects with Chiari network by clinical diagnosis $(n=90)$.

\begin{tabular}{lcccc}
\hline Clinical diagnosis & \multicolumn{2}{c}{ Differentiation of Chiari network } & \multirow{2}{*}{$\begin{array}{c}\text { Total } \\
\text { Number (\%) }\end{array}$} \\
\cline { 2 - 4 } & $\begin{array}{c}\text { Well } \\
\text { Number (\%) }\end{array}$ & $\begin{array}{c}\text { Moderate } \\
\text { Number (\%) }\end{array}$ & $\begin{array}{c}\text { Poor } \\
\text { Number (\%) }\end{array}$ & \\
\hline Normal & $19(21.1)$ & $14(15.6)$ & $17(18.9)$ & $50(55.6)$ \\
Congenital heart disease & $5(5.6)$ & $1(1.1)$ & 0 & $6(6.7)$ \\
Valvular heart disease & $2(2.2)$ & 0 & $1(1.1)$ & $3(3.3)$ \\
Ischemic heart disease & $6(6.7)$ & $9(10)$ & $3(3.3)$ & $18(20)$ \\
Cardiomyopathies & $5(5.6)$ & $2(2.2)$ & 0 & $7(7.8)$ \\
Others & $4(4.4)$ & $2(2.2)$ & 0 & $6(6.7)$ \\
\hline
\end{tabular}

Table-II

Relationship between age group and clinical diagnosis of the study subjects with Chiari network $(n=90)$.

\begin{tabular}{lccccccc}
\hline $\begin{array}{l}\text { Age Group } \\
\text { (Years) }\end{array}$ & \multicolumn{6}{c}{ Clinical diagnosis } & Total \\
\cline { 2 - 6 } & $\begin{array}{c}\text { Normal } \\
\text { Number (\%) }\end{array}$ & $\begin{array}{c}\text { Congenital } \\
\text { Number (\%) }\end{array}$ & $\begin{array}{c}\text { Valvular } \\
\text { Number (\%) }\end{array}$ & $\begin{array}{c}\text { IHD } \\
\text { Number (\%) }\end{array}$ & $\begin{array}{c}\text { Cardiomyopathy } \\
\text { Number (\%) }\end{array}$ & $\begin{array}{c}\text { Others } \\
\text { Number (\%) }\end{array}$ & Number (\%) \\
\hline$<41$ & $23(25.6)$ & $4(4.4)$ & $1(1.1)$ & $2(2.2)$ & $1(1.1)$ & $4(4.4)$ & $35(38.9)$ \\
$41-60$ & $17(18.9)$ & 0 & $1(1.1)$ & $9(10)$ & $3(3.3)$ & $1(1.1)$ & $31(34.4)$ \\
$61-80$ & $10(11.1)$ & $2(2.2)$ & $1(1.1)$ & $5(5.6)$ & $3(3.3)$ & 0 & $21(23.3)$ \\
$>80$ & 0 & 0 & 0 & $2(2.2)$ & 0 & $1(1.1)$ & $3(3.3)$ \\
\hline Total & $50(55.6)$ & $6(6.7)$ & $3(3.3)$ & $18(20)$ & $7(7.8)$ & $6(6.7)$ & $90(100)$ \\
\hline
\end{tabular}

\section{Discussion:}

Chiari network was first described by Hans Chiari, an Austrian pathologist, in 13 human right atria in $1897 .{ }^{11}$ Since then; its prevalence has been reported sporadically. Schneider et al. conducted a prevalence study on Chiari network based on trans-oesophageal echocardiography (TOE); the prevalence was $2 \%$ (29 of 1,436 patients). ${ }^{4}$ In their study, Bhatnagar et al. found Chiari network in $13.6 \%$ of the 213 cadaver hearts, 
and $10.5 \%$ of the 38 autopsied hearts examined. ${ }^{3}$ This apparent disparity in prevalence may be due to the way of diagnosing the Chiari network, i.e. imaging modality or cadaveric heart. However, the incidence of Chiari network in a more recent study involving 80 cadaveric hearts was $3.75 \% .{ }^{12}$ Another explanation behind the varying prevalence may be the criteria used for defining Chiari network. All structures found in the right atrium in relation to the IVC or coronary sinus is not well visualized, especially in imaging study. In fact, the prevalence of Chiari network of $4.91 \%$ found in the present study comes down to $3.77 \%$ when the poorly-visualized structures are excluded from calculation.

Chiari network is often regarded as an 'innocuous bystander' diagnosed incidentally. However, this structure is being increasingly recognized to have clinical importance - both diagnostic as well as therapeutic. This right atrial network may occasionally mimic thrombus, vegetation or mass. ${ }^{13-16}$ From the therapeutic point of view, Chiari network has been reported to be associated with thromboembolism, ${ }^{7}$ infective endocarditis, ${ }^{6}$ arrhythmia, ${ }^{7}$ and others. Contrarily, the sieve-like structure of Chiari network might play protective role against migration or propagation of thrombus formed in IVC to cause pulmonary embolism. ${ }^{19}$ During intervention including electrophysiological study and radiofrequency ablation, the catheter or guidewire may get entangled into the $\mathrm{CN}$, causing procedural complications. ${ }^{20-22}$

In our observation, among the subjects with Chiari network, $20 \%$ had ischaemic heart disease, $7.8 \%$ had cardiomyopathy, $6.7 \%$ had congenital heart disease while $3.3 \%$ had valvular heart disease. Again, 4 patients had haemoglobinopathy, 2 patients hypertrophic cardiomyopathy, 2 patients atrial septal defect, 1 patient atrial septal aneurysm, and 1 patient had complex congenital heart disease (transposition of great arteries, ventricular septal defect and pulmonary stenosis). One of the 90 patients with Chiari network, a 45-yearold man, presented with pulmonary embolism, and he had well-developed Chiari network. Previously, Chiari network has been reported in association with other congenital heart diseases, e.g., atrial septal defect and anomalous pulmonary venous drainage, atrial septal aneurysm, and Ebstein anomaly of tricuspid valve. ${ }^{9}$ Interestingly, we have found 4 cases of haemoglobinopathy having Chiari network; whether this observation is merely casual or a positive association needs further study.

The study has got some limitations. Echocardiographic evaluation was done on the referred adult patients who may not be representative of the general population. Also, only transthoracic echocardiography was utilized in this study; the prevalence of Chiari network may differ from that we have found if transoesophageal and 3-dimentional modalities would have been used. However, to the best of our knowledge, this is the first attempt to find out the prevalence of Chiari network and its association in Bangladeshi population.

\section{Conclusion:}

The Chiari network is often an incidental diagnosis, though it may not be so rare. This apparently normal anatomical variant may cause diagnostic confusion and have therapeutic implications. It may be associated with other conditions like congenital heart disease, hypertrophic cardiomyopathy, arrhythmia or even haemoglobinopathy. Whether these co occurrences are merely casual or positive association needs further evaluation. Chiari network may predispose to thromboembolism, even pulmonary embolism. Clinicians should have appropriate preparedness while doing echocardiography to avoid diagnostic dilemma, while performing cardiovascular interventions to overcome difficulties, and while dealing with patients to make the appropriate diagnosis.

Conflict of Interest - None.

\section{Acknowledgement:}

Ms. Nusrat Zahan, Echo Lab Assistant, Popular Diagnostic Centre Ltd. (Shyamoli Branch), Dhaka.

\section{References:}

1. Goedde TA, Conetta D, Rumisek JD. Chiari network entrapment of thromboemboli: congenital inferior vena cava filter. Ann Thorac Surg 1990 (Feb); 49(2): 317-318.

2. Goldschlager A, Goldschlager N, Brewster H, Kaplan J. Catheter entrapment in a Chiari network involving an atrial septal defect. Chest 1972 (Sep); 62(3): 345-346. 
3. Bhatnagar KP, Nettleton GS, Campbell FR, Wagner CE, Kuwabara N, Muresian H. Chiari anomalies in the human right atrium. Clin Anat 2006;19: 510-516.

4. Schneider B, Hofmann T, Justen MH, Meinertz T. Chiari's network: normal anatomic variant or risk factor for arterial embolic events. J Am Coll Cardiol 1995; 26: 203-210.

5. Yater WM. The paradox of Chiari's network. Review and report of a case of Chiari's network ensnaring a large embolus. Am Heart J 1936; 11: 542-552.

6. Figueras-Coll M, Sabaté-Rotés A, Cañete-Abajo N, Domènech-Ximenos $\mathrm{B}$. The Chiari network-only an embryonic remnant or a confusing finding? World J Pediatr Congenit Heart Surg 2017 (Jan 1):2150135117704658.

7. Schwimmer-Okike N, Niebuhr J, Schramek GG, Frantz $\mathrm{S}$, Kielstein $\mathrm{H}$. The presence of a large Chiari network in a patient with atrial fibrillation and stroke. Case Rep Cardiol 2016; 2016: 4839315.

8. Carrena O, Oluoha O, Wahba A, Eshun D, Endsley M, Okafor H. Complicated infective endocarditis limited to a Chiari network. Case Rep Cardiol 2018 (Jun 26); 2018: 3837825.

9. Islam AKMM, Sayami LA, Zaman S. Chiari network: A case report and brief overview. J Saudi Heart Assoc 2013; 25: 225-229.

10. Chu S, Solheim E, Chen J, Hoff PI, Schuster P. Entrapment and retrieval of a diagnostic electrophysiological catheter in the Chiari network. J Arrhythm 2018 Sep 3; 34(6): 647 649 .

11. Chiari H. Ueber Netzbildungen im rechten Vorhof edes Herzens. Beitr Pathol Anat 1897; 22:1-10.

12. Jansirani DD, Deep SS, Anandaraja S. Anatomical study of Chiari network and the remnant of left venous valve in the interior of right atrium. Anat Res Int 2015; 2015: 247680 .

13. Fredericks P, Liu T, Colla J. Right atrial thrombus or Chiari network? Clin Pract Cases Emerg Med 2017 (May 9); 1(3): 258-259.

14. Erdogan SB, Akansel S, Sarg1n M, Mete MET, Arslanhan G, Aka SA. A case of a large Chiari network mimicking a right atrial thrombus. North Clin Istanb 2017 Oct 18; 4(3): 270-272.
15. Mayr A, Klug G, Greulich S, Metzler B, Feuchtner G. Serpentine-like right atrial mass and fulminant bilateral pulmonary embolism during treatment with rivaroxaban. Int J Cardiovasc Imaging 2016 (Jun); 32(6): 1001-1002.

16. Moral S, Ballesteros E, Huguet M, Panaro A, Palet J, Evangelista A. Differential diagnosis and clinical implications of remnants of the right valve of the sinus venosus. J Am Soc Echocardiogr 2016 (Mar); 29(3): 183-194.

17. Alekhin MN, Vaniev SB, Pavlov AV, Nosenko EM, Kriuchkova OV, Sidorenko BA. [Chiari network and pulmonary embolism]. Kardiologiia 2015; 55(1): 88-91. [Article in Russian]

18. Rochlani Y, Klair J, Vallurupalli S, Kenchaiah S. Chiari network and aortic valve endocarditis with concurrent pulmonary and systemic embolization. CASE (Phila) 2017 Feb; 1(1): 37-40.

19. Obaji SG, Cooper R, Somauroo J. Chiari network: a protective filter against pulmonary embolism in a case of polycythaemia. BMJ Case Rep 2012 (Apr); 28: 2012. pii: bcr0520114289.

20. Aung H, Espinosa RE, Powell BD, McLeod CJ. Entrapment of a pacing lead within a Chiari network: Utility of intracardiac echo and a laser sheath. Pacing Clin Electrophysiol 2016 (Jun); 39(6): 620-622.

21. Yoshimura M, Toriumi T. Guidewire entrapment in the Chiari network. J Cardiothorac Vasc Anesth 2016 Jun; 30(3): e24-25.

22. Cooke JC, Gelman JS, Harper RW. Chiari network entanglement and herniation into the left atrium by an atrial septal defect occluder device. J Am Soc Echocardiogr 1999 (Jul); 12(7): 601-603.

23. Cloez JL, Neimann JL, Chivoret G, Danchin N, Bruntz JF, Godenir JP, et al. Echographic rediscovery of an anatomical structure: the Chiari network. Apropos of 16 cases. [Article in French] Arch Mal Coeur Vaiss 1983 (Nov); 76(11): 1284-1292.

24. Gnecco G, Bezante GP, Pastorini C, Caponnetto S. Echocardiographic findings in interatrial septal aneurysm, Chiari's network and tricuspid valve prolapse. An unusual association. [Article in Italian]. Minerva Cardioangiol 1990 (Oct); 38(10): 443-445. 